\title{
On the Digital Road to Improved Home Healthcare
}

Thomas F. Osborne, MD

Joel J. Reich, MD

Bryan T. Arkwright, MHA

John Russo, Jr, PharmD

Editor's note: This is the first in a series of articles covering technological advancements in home healthcare. Here, the authors provide an overview. Subsequent articles will expand on the details of individual subtopics.

Treating illness at home is a tradition that has recently been revitalized by a number of factors. Specifically, telecommunication tools, financial imperatives, quality initiatives, staffing constraints, and patient preference are among the leading drivers for this transition. Successful program outcomes depend on a number of issues, with knowledge, leadership, and management being paramount. Technological advancements will change the way we practice medicine and facilitate the effective transition to homecare in select populations.

\section{Historical Perspective}

Up until the early 19 th century, the United States economy was primarily agricultural. In this often expansive rural landscape, most healthcare was provided by a household member, who was sometimes relegated to the role of fulltime caregiver. Although there were limited institutions for the sick in urban areas during this time period, they were primarily intended for the marginalized and poor.

Medical scientific advancement, development of professional standards, and improved facility conditions, enhanced the credibility of hospitals which dramatically grew in number from 120 hospitals in 1873 to 4,300 in $1909 .{ }^{1-6}$ Amid this growing popularity of hospital based care, the 'house call' remained a dominant factor for a short period, 
accounting for $40 \%$ of encounters in 1930 , but falling rapidly to $10 \%$ in 1950 s, and reaching less than $1 \%$ of older patients in the 1990 s. $^{7}$

\section{Cost Pressures}

The unsustainable increasing costs of hospital-based care has prompted numerous federal policy changes. For example, in 1983 Medicare dramatically changed reimbursement policy with a newly implemented payment system of 'diagnosis-related groups' which reimburses hospitals based on the expected complexity of care and not number of days. This historic change has incentivized hospitals to discharge patients as soon as possible. ${ }^{8}$ However, the costs for transitional and long-term healthcare options outside of the hospital are also high, with recent U.S. estimates ranging between $\$ 210.9$ billion $^{9}$ and $\$ 317.1$ billion annually. ${ }^{10}$ Of further concern, the number of people utilizing these types of services is projected to increase from 15 million in the year 2000 to 27 million in the year 2050. ${ }^{11}$ Therefore, this extraordinary financial burden is a major concern for all stakeholders, ${ }^{12-14}$ and as a result, efficiently caring for these patients is becoming an increasingly important topic in healthcare reform and policy. ${ }^{15-18} \mathrm{Home}$ telehealth programs offer an appealing alternative or extension to subacute care centers and long-term care or nursing home facilities. With appropriate discharge planning and coordinated follow up, effective home health programs may also reduce the likelihood of hospital readmission. Even though telehealth programs have the potential to dramatically reduce cost, lagging federal reimbursement policies are a barrier to implementation.

\section{Shift Back to Home Healthcare}

There are additional overarching benefits which are driving the shift back toward home based care. From a clinical perspective, providing care in a patient's own residence reduces the risk of acquiring nosocomial infections, which may be antibiotic resistant. In addition, there are clinical conditions ranging from Alzheimer disease to autism, which may be more effectively treated in the home. Geographic disparities that would otherwise limit access to specialist may also be eliminated and thereby making healthcare more equitable. ${ }^{8}$ Virtual visits also improve access to basic care by 
overcoming transportation constraints which may otherwise limit the ability for patients to participate in routine follow-up. In addition, wellness programs and preventive measures may be more accessible and utilized to a greater extent if made available in the home. Importantly, a digitally connected home can empower independence and promote a sense of security. It is therefore not surprising that there is a growing desire among many consumers to shift their healthcare to the familiar comfort and convenience of their own residence..$^{17-19}$

\section{Spectrum of Home Health Patients}

Currently, the majority of home health services address the chronic needs of older patients. ${ }^{20-22}$ As a result, the majority of diseases encountered in this setting parallel national geriatrics demographics, with home telehealth services for diabetes, hypertension, heart disease, stroke, cancer, arthritis, COPD, atrial fibrillation, dementia, and depression encountered at the highest frequency. ${ }^{23}$

Although elderly long-term care is projected to be a major target for home health services, the same basic concepts and infrastructure may be transferrable to different patient populations. To this end, numerous programs are being developed for other health needs ranging from urgent care, pediatrics, rehabilitation medicine, and general wellness. ${ }^{24-26}$

\section{Technological Advances}

Fortunately, recent technological advances in miniature sensors, low-power integrated circuits, and wireless communications have enabled the development of low-cost mobile health data gathering tools that can efficiently monitor many specific illnesses. ${ }^{27,28}$

In addition to technological solutions designed for individual diseases, there is also a growing need to manage more complex patients with multiple illnesses. ${ }^{29}$ In this situation, it is not uncommon for patients to have several caregivers to address a variety of ailments and comorbidities. Unfortunately, when there are different specialists working in isolation, an unintended consequence may be uncoordinated care that can 
lead to life-threating problems such as inappropriate polypharmacy, the incidence of which is high in older home health patients. ${ }^{30-33}$ This challenge underscores the need for an integrated and interoperable enterprise health information platform that connects caregivers and facilities to help prevent medical errors.

\section{Providing Value}

Healthcare providers are being asked to do more with the same or decreased funding and resources. Many health specialties are also projected to have major shortages in staffing which, if not augmented by technological advancement, will result in poorer patient outcomes. ${ }^{34-37}$ At the same time, patients and payors are looking for greater value in both outcomes and overall experience.

The above factors directly relate to the principals of the "Triple Aim," which specifically calls for enhanced patient experience, improved health, and reduced per capita cost of care (Figure 1). ${ }^{38}$ These three key objectives are also particularly pertinent to the overall goals of digitally connected home healthcare.

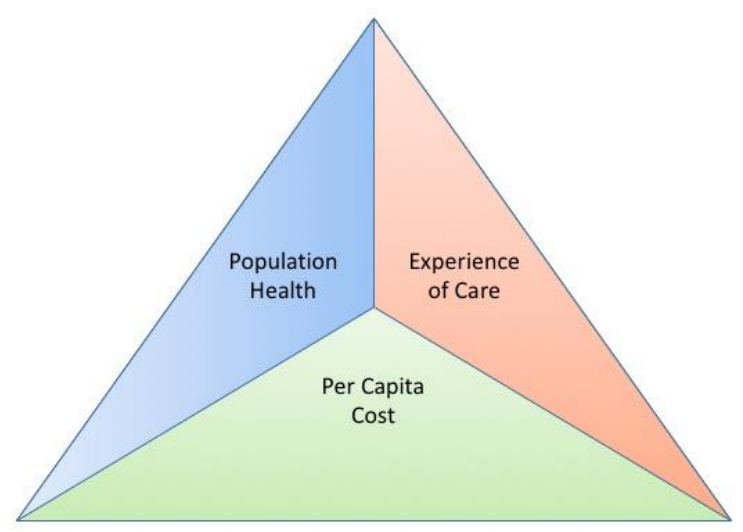

Figure 1. Developed by the Institute for Healthcare, the IHI Triple Aim is a framework that describes an approach to optimizing health system performance. 
As an example, a pillar to many home health programs is remote video technology, which has been shown in many cases to be well received, cost-effective, and improve health. ${ }^{39,40}$

Although the promise of telehealth may seem intuitively obvious, there is also a critical need to continually and objectively evaluate assumptions. For example, a recent analysis reviewed 36 journal articles and found telehealth to be more expensive in $31 \%$ of cases. Importantly, the article authors suggested that the specific organizational model employed in the delivery of care was more important to the success of the program than the type of technology utilized. ${ }^{41}$ In a separate study, the authors suggested that the lack of an effective infrastructure for case management was the pivotal factor in the lack of reportable benefit to telehealth monitoring. ${ }^{15}$ These examples underscore the fact that technology by itself is not effective and tools need to be tested and implemented with the primary goal of quality patient-centered care. In the words of Jeffrey K. Liker, "Use only reliable, thoroughly tested technology that serves your people and processes". ${ }^{42}$

\section{Leadership and Management}

The skills of leadership and management are critically important to success because it can take as much time to implement the right solution as it does to create the wrong one. To this end, the required interplay between change and order are dependent on a number of complementary factors including clear communication, vision, empowerment, strategy, alignment and a deep understanding of the healthcare environment, as well as thoughtful evaluation, planning, requirements gathering, structure, and stakeholder involvement. ${ }^{42-45}$

Specific considerations such as potential technical limitations in broadband internet connectivity, interoperability with critical systems, the need for uniform standards between electronic health records, cost, relevance of the proposed solutions, reliability, user acceptance, as well as legal, ethical and facility-organizational factors need to be addressed. Understanding these types of variables and requirements will reveal 
valuable information about the most successful path to implementation as well as the projected benefits and impacts. ${ }^{46}$

Planning for long-term maintenance and continual improvements based on open feedback and ongoing evaluation are also key factors to long-term achievement and sustainability. ${ }^{47,48}$

\section{User Acceptance}

The success of any program depends on user acceptance. In the case of technologically-enabled home healthcare, the end-users are varied and include patients, caregivers, support staff, and administrators. ${ }^{49}$ To be successful, the solutions must meet the needs of each major stakeholder. Thoughtfully designed user interfaces tailored to the specific audience promote an effective, intuitive, and enjoyable experience, which also decreases the need for training and elaborate change management strategies. Tools should improve upon an existing framework and not produce an environment where people become subservient to technology. ${ }^{42}$

These issues are particularly pertinent to home caregivers who may already be overworked; home health nurses work more hours than nurses in nearly any other setting. ${ }^{50}$ Importantly, it has been shown that improved managerial support of nursing practice and better relations with physicians, can translate to improved morale and patient outcomes. ${ }^{51,52}$ Therefore, technological communication tools that bridge these gaps may also provide nonlinear paths to improved patient care.

\section{Operational Challenges of Telehealth}

The intrinsic geographically isolated nature of home healthcare requires advanced tools for the coordinated collaboration of patients, cross-functional teams, tools, and disciplines. To this end, a successfully implemented technological infrastructure is required to provide a platform for efficient communication and engagement for everyone involved. 
Therefore, the availability and reliability of internet connections is a potential critical limitation to the deployment of specific solutions such as synchronous videoconferencing and biometrics tracking. ${ }^{53,54}$ Nonetheless, in situations of limited internet access, a less desirable delayed information transfer to caregivers can still be achieved asynchronously in a "store-and-forward" process.

The connected benefits of telehealth also come with concerns regarding the security of protected health information that will be digitally transferred to offsite caregivers. ${ }^{55,57}$ In addition, the various patient health metrics obtained will need to be presented to caregivers in an efficient, user-friendly format. ${ }^{58,59}$

Even with the most robust technical infrastructure, periodic in-person home visits by a caregiver are often part of a complete home health solution. However, the unstandardized home environment presents efficiency and safety challenges to visiting healthcare examiners and these issues also need to be systematically addressed. ${ }^{54}$ In addition, the use of relatively low tech options such as railings, adjustable shower seats, and motion activated lights provide important levels of added patient safety and independence that should not be overlooked.

\section{Future Technology Directions}

Iterative improvements of existing technological solutions will drive greater value and user acceptance to this disruptive care model. However, new developments in the fields of machine learning, artificial intelligence, analytics, integrated networks, and robotics will drive a paradigm shift in how we practice medicine.

\section{Conclusion}

A number of interdependent factors have made home healthcare an attractive option for many. Leadership, management and technology are among key factors for success. Home telehealth programs not only hold the potential to solve an escalating demand at a lower cost, but also may achieve that goal with significantly improved outcomes. 


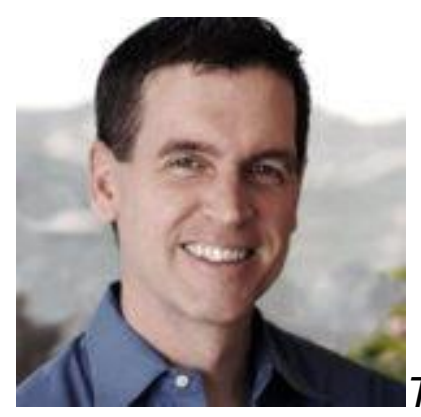

Thomas F. Osborne, MD, is Director of Medical Informatics at vRad (Virtual Radiologic), the leading teleradiology services and telemedicine company, which leverages its proprietary technology, data, and analytics capabilities to rapidly move patient images and information across a secure global network of 2,100 medical facilities in all 50 states.

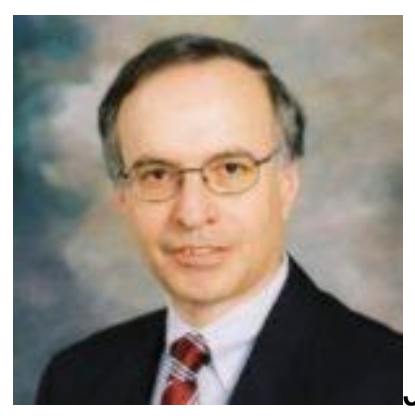

Joel J. Reich, MD, FACEP, is Chief Medical Officer of Eastern

Connecticut Health Network.

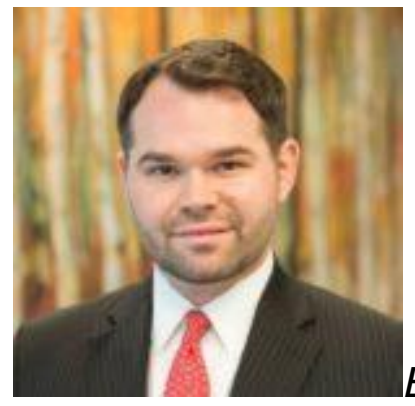

Bryan T. Arkwright, MHA, is Senior Consultant with Schumacher Clinical Partners, focusing on Telehealth/Telemedicine Strategy and Operations. 


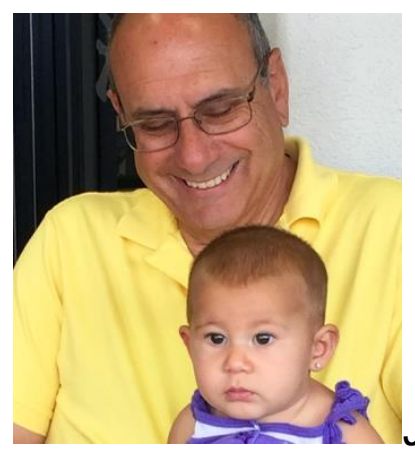

Medicine Today.

Dr. Osborne conceived the idea for this series of articles. He, Dr. Reich, and Mr. Arkwright contributed to the content. Dr. Russo provided editorial support.

Tags: elderly, financial burden, geriatrics, healthcare providers, home healthcare, home telehealth, home telemedicine, hospital-based treatment, how does telehealth enhance the doctor patient relationship, information transfer, long-term care, remote video technology, rural, technological advances, technologically-enabled home healthcare, telehealth services, telemedicine process improvement, telemedicine program implementation, telemedicine remote health, Triple Aim, user acceptance, what is telemedicine and how does it work.

\section{References}

1. Porter, R. (1999). The Greatest Benefit to Mankind: A Medical History of Humanity (The Norton History of Science). WW Norton \& Company.

2. Risse, G. B. (1999). Health care in hospitals: the past 1000 years. The Lancet, 354, SIV25.

3. Porter, D. (Ed.). (1994). The History of Public Health and the Modern State (Vol. 26). Rodopi.

4. Ding, A. (2013). The History of Health Care in the United States Pre-1965. In: An Introduction to Health Policy (pp. 3-13). Springer New York. 
5. Abel, E. K. (1995). A "terrible and exhausting" struggle: family caregiving during the transformation of medicine. Journal of the History of Medicine and Allied Sciences, 50(4), 478-506.

6. Finzsch, N., \& Jütte, R. (2003). Institutions of Confinement: Hospitals, Asylums, and Prisons in Western Europe and North America, 1500-1950. Cambridge University Press.

7. Daschle, T., \& Dorsey, E. R. (2015). The return of the house call. Annals of Internal Medicine, 162(8), 587-588.

8. Goldfield, N. (2010). The evolution of diagnosis-related groups (DRGs): from its beginnings in case-mix and resource use theory, to its implementation for payment and now for its current utilization for quality within and outside the hospital. Quality Management in Healthcare, 19(1), 3-16.

9. O'Shaughnessy, C. V. (2013). The Basics: National Spending for Long-Term Services and Supports. 2012. Washington, DC: National Health Policy Forum, George Washington University. Available from: http://www.nhpf.org/library/thebasics/Basics_LTSS_03-27-14.pdf.

10. Colello, K. J., Mulvey, J., \& Talaga, S. R. (2013, April). Long-term services and supports: Overview and financing. In Congressional Research Service Report for Congress. Available from: http://digital.library.unt.edu/ark:/67531/ metadc462393/m1/1/high_res_d/R42345_2013Apr04.pdf.

11. US Department of Health and Human Services. (2003). The future supply of longterm care workers in relation to the aging baby boom generation: Report to Congress. Washington DC: US DHHS. Available from: https://aspe.hhs.gov/sites/default/files/pdf/72961//". 
12. Bipartisan Policy Center. America's long-term care crisis: Challenges in financing and delivery. 2014. Available from: http://bipartisanpolicy.org/wpcontent/uploads/2014/03/BPC-Long-Term-Care-Initiative. pdf

13. Reinhard, S. C., Kassner, E., Houser, A., \& Mollica, R. (2011). Raising expectations: A state scorecard on long-term services and supports for older adults, people with physical disabilities, and family caregivers. Washington, DC: AARP. Available from: http://www.longtermscorecard.org/ /me.

14. U.S. Senate Commission on Long-Term Care. Report to the Congress. 2013. Available from: http://www. gpo.gov/fdsys/pkg/GPO-LTCCOMMISSION/pdf/GPOLTCCOMMISSION.pdf.

15. Takahashi, P. Y., Pecina, J. L., Upatising, B., Chaudhry, R., Shah, N. D., Van Houten, H., ... \& Hanson, G. J. (2012). A randomized controlled trial of telemonitoring in older adults with multiple health issues to prevent hospitalizations and emergency department visits. Archives of Internal Medicine, 172(10), 773-779.

16. White House Conference on Aging Staff. Long-term services and supports policy brief.," In: 2015 White House Conference on Aging. Washington, DC: U.S. Department of Health and Human Services. 2015.

17. Doty, P. (2010). The evolving balance of formal and informal, institutional and noninstitutional long-term care for older Americans: A thirty-year perspective. Public Policy \& Aging Report, 20(1), 3-9.

18. Wiener, J. M. (2013). After CLASS: The long-term care commission's search for a solution. Health Affairs, 32(5), 831-834. 
19. Cusack, C. M., Pan, E., Hook, J. M., Vincent, A., Kaelber, D. C., \& Middleton, B. (2008). The value proposition in the widespread use of telehealth. Journal of Telemedicine and Telecare, 14(4), 167-168.

20. Harris-Kojetin, L., Sengupta, M., Park-Lee, E., Valverde, R., Caffrey, C., Rome, V., \& Lendon, J. (2016). Long-Term Care Providers and Services Users in the United States: Data From the National Study of Long-Term Care Providers, 2013-2014. Vital \& health statistics. Series 3, Analytical and epidemiological studies/[US Dept. of Health and Human Services, Public Health Service, National Center for Health Statistics], (38), 1-118.

21. Haupt, B. J., \& Jones, A. (1999). The National Home and Hospice Care Survey: 1996 summary. Vital and health statistics. Series 13, Data from the National Health Survey, (141), 1-238.

22. Gordy, S., \& Trunkey, D. (2014). Changing Demographics of the American Population. In Geriatric Trauma and Critical Care (pp. 3-9). Springer New York.

23. Centers for Medicare and Medicaid Services. Chronic Condition Data Warehouse. West Des Moines, IA: Buccaneer, A General Dynamics Company; 2012. Chronic condition categories. (Available from: http://www.ccwdata.org/chronicconditions/index.htm).

24. Elias, E. R., Murphy, N. A., Liptak, G. S., Adams, R. C., Burke, R., Friedman, S. L., ... \& Norwood, K. W. (2012). Home care of children and youth with complex health care needs and technology dependencies. Pediatrics, 129(5), 996-1005.

25. Hewitt-Taylor, J. (2012). Planning the transition of children with complex needs from hospital to home. Nursing Children and Young People, 24(10), 28. 
26. Patel, S., Park, H., Bonato, P., Chan, L., \& Rodgers, M. (2012). A review of wearable sensors and systems with application in rehabilitation. Journal of Neuroengineering and Rehabilitation, 9(1), 1.

27. Baig, M. M., \& Gholamhosseini, H. (2013). Smart health monitoring systems: an overview of design and modeling. Journal of Medical Systems,37(2), 1-14.

28. Milenković, A., Otto, C., \& Jovanov, E. (2006). Wireless sensor networks for personal health monitoring: Issues and an implementation. Computer Communications, 29(13), 2521-2533.

29. Salive, M. E. (2013). Multimorbidity in older adults. Epidemiologic Reviews, mxs009.

30. Maher, R. L., Hanlon, J., \& Hajjar, E. R. (2014). Clinical consequences of polypharmacy in elderly. Expert Opinion on Drug Safety, 13(1), 57-65.

31. Scott, I. A., Hilmer, S. N., Reeve, E., Potter, K., Le Couteur, D., Rigby, D., ... \& Jansen, J. (2015). Reducing inappropriate polypharmacy: the process of deprescribing. JAMA Internal Medicine, 175(5), 827-834.

32. Bronskill, S. E., Gill, S. S., Paterson, J. M., Bell, C. M., Anderson, G. M., \& Rochon, P. A. (2012). Exploring variation in rates of polypharmacy across long term care homes. Journal of the American Medical Directors Association, 13(3), 309-e15.

33. Bao, Y., Shao, H., Bishop, T. F., Schackman, B. R., \& Bruce, M. L. (2012). Inappropriate medication in a national sample of US elderly patients receiving home health care. Journal of General Internal Medicine, 27(3), 304-310.

34. Kalisch, B. J., Tschannen, D., \& Lee, K. H. (2012). Missed nursing care, staffing, and patient falls. Journal of Nursing Care Quality, 27(1), 6-12. 
35. Hirsbrunner, T., Denhaerynck, K., Fierz, K., Milisen, K., \& Schwendimann, R. (2015). Nurse staffing, patient turnover and safety climate and their association with inpatient falls and injurious falls on medical acute care units: a cross-sectional study. Journal of Hospital Administration, 4(3), p54.

36. Dumanovsky, T., Rogers, M., Spragens, L. H., Morrison, R. S., \& Meier, D. E. (2015). Impact of Staffing on Access to Palliative Care in US Hospitals. Journal of Palliative Medicine, 18(12), 998-999.

37. Rimsza, M. E., Hotaling, A. J., Keown, M. E., Marcin, J. P., Moskowitz, W. B., Sigrest, T. D., \& Simon, H. K. (2015). The use of telemedicine to address access and physician workforce shortages. Pediatrics, 136(1), 202-209.

38. Institute for Healthcare Improvement. The IHI Triple Aim. URL:

http://www.ihi.org/engage/initiatives/tripleaim/pages/default.aspx. Accessed 8/14/16.

39. Johnston, B., Weeler, L., Deuser, J., \& Sousa, K. H. (2000). Outcomes of the Kaiser Permanente tele-home health research project. Archives of Family Medicine, 9(1), 40.

40. Pinciroli, F., Corso, M., Fuggetta, A., Masseroli, M., Bonacina, S., \& Marceglia, S. (2011). Telemedicine and e-health. IEEE pulse, 2(3), 62-70.

41. Wade, V. A., Karnon, J., Elshaug, A. G., \& Hiller, J. E. (2010). A systematic review of economic analyses of telehealth services using real time video communication. $B M C$ health services research, 10(1), 1.

42. Liker, J. K. (2004). The Toyota Way. McGraw-Hill Education.

43. Collins, J. C. (2001). Good to Great: Why Some Companies Make the Leap... and Others Don't. Random House. 
44. Ploeg, J., Davies, B., Edwards, N., Gifford, W., \& Miller, P. E. (2007). Factors Influencing Best-Practice Guideline Implementation: Lessons Learned from Administrators, Nursing Staff, and Project Leaders. Worldviews on Evidence-Based Nursing, 4(4), 210-219.

45. Kearns, G. S., \& Sabherwal, R. (2006). Strategic alignment between business and information technology: a knowledge-based view of behaviors, outcome, and consequences. Journal of Management Information Systems,23(3), 129-162.

46. Koch, S. (2006). Home telehealth-current state and future trends. International Journal of Medical Informatics, 75(8), 565-576.

47. Finkbeiner, M., Schau, E. M., Lehmann, A., \& Traverso, M. (2010). Towards life cycle sustainability assessment. Sustainability, 2(10), 3309-3322.

48. Wheelwright, S. C., \& Clark, K. B. (1992). Creating project plans to focus product development. Harvard Business School Pub.

49. Cimperman, M., Brenčič, M. M., Trkman, P., \& Stanonik, M. D. L. (2013). Older adults' perceptions of home telehealth services. Telemedicine and e-Health, 19(10), 786-790.

50. US Department of Health and Human Services, \& US Department of Health and Human Services. (2010). The registered nurse population: Findings from the 2008 national sample survey of registered nurses. Health Resources and Services Administration, (ed.). US Department of Health and Human Services.

51. Lake, E. T., \& Friese, C. R. (2006). Variations in nursing practice environments: relation to staffing and hospital characteristics. Nursing Research, 55(1), 1-9. 
52. Flynn, L., Dickson, G., \& Moles, D. J. (2007). Focus on caregiving. Enhancing the nursing workplace: In a recent study of long term care nurses, key organizational factors emerge as most important in supporting a productive work environment. Provider, 33(1), 35-9.

53. Perrin, A., \& Duggan, M. (2015). Americans' internet access: 2000-2015.Pew Research Center, 26. Available from http://www. pewinternet. org/2015/06/26/americans-internet-access-2000-2015. 2015

54. Gindi, R. M., Zipf, G., Galinsky, A. M., Miller, I. M., Nwankwo, T., \& Terry, A. L. (2014). Comparison of in-home collection of physical measurements and biospecimens with collection in a standardized setting: the health measures at home study. Vital and health statistics. Series 2, Data evaluation and methods research, (164), 1-16.

55. Wilkowska, W., \& Ziefle, M. (2012). Privacy and data security in E-health: Requirements from the user's perspective. Health Informatics Journal, 18(3), 191-201.

56. Luxton, D. D., Kayl, R. A., \& Mishkind, M. C. (2012). mHealth data security: The need for HIPAA-compliant standardization. Telemedicine and e-Health, 18(4), 284-288.

57. Kotz, D., Gunter, C. A., Kumar, S., \& Weiner, J. P. (2016). Privacy and Security in Mobile Health: A Research Agenda. Computer, 49(6), 22-30.

58. Fleming, N. S., Becker, E. R., Culler, S. D., Cheng, D., McCorkle, R., Graca, B. D., \& Ballard, D. J. (2014). The impact of electronic health records on workflow and financial measures in primary care practices. Health Services Research, 49(1pt2), 405420.

59. Page, C. A. K., \& Schadler, A. (2014). A nursing focus on EMR usability enhancing documentation of patient outcomes. Nursing Clinics of North America, 49(1), 81-90. 
1656. Osborne et al. On the Digital

https://doi.org/10.30953/tmt.v1.80

Page 17 of 17 